University of San Diego

Digital USD

Spring 2-1-2016

\title{
The Effect of Personal Portable Alarms on Clinical Staff's Perception of Safety at an Adult Psychiatric Hospital Unit
}

Kornelia A. Kopec

kkopec@sandiego.edu

Follow this and additional works at: https://digital.sandiego.edu/dnp

Part of the Psychiatric and Mental Health Nursing Commons

\section{Digital USD Citation}

Kopec, Kornelia A., "The Effect of Personal Portable Alarms on Clinical Staff's Perception of Safety at an Adult Psychiatric Hospital Unit" (2016). Doctor of Nursing Practice Final Manuscripts. 3.

https://digital.sandiego.edu/dnp/3

This Doctor of Nursing Practice Final Manuscript is brought to you for free and open access by the Theses and Dissertations at Digital USD. It has been accepted for inclusion in Doctor of Nursing Practice Final Manuscripts by an authorized administrator of Digital USD. For more information, please contact digital@sandiego.edu. 
INCREASING STAFF'S PERCEPTION OF SAFETY USING PERSONAL PORTABLE ALARMS: ADULT PSYCHIATRIC HOSPITAL UNIT

UNIVERSITY OF SAN DIEGO

Hahn School of Nursing and Health Science

\title{
DOCTOR OF NURSING PRACTICE PORTFOLIO
}

by

Kornelia A Kopec

\author{
A Portfolio presented to the \\ FACULTY OF THE HAHN SCHOOL OF NURSING AND HEALTH SCIENCE \\ UNIVERSITY OF SAN DIEGO \\ In partial fulfillment of the \\ requirement for the degree \\ DOCTOR OF NURSING PRACTICE \\ May/2016
}




\section{Opening Statement}

Today Nurse Practitioners function as clinicians, leaders, researchers, educators, managers and policymakers. As a Doctorally prepared Adult and Geriatric NP I wish to prepare myself for the role of a2 clinician, educator, a change maker, trailblazer, policymaker and hopefully motivator and a mentor to other nurses. My experience as a nurse began 10 years ago as a navy Nurse Corps Commissioned Officer in the specialty of medical and surgical oncology. As a brand new nurse graduate I found the learning curve was steep in the military service and in the ever-growing field of cancer care. I soon realized lifelong learning is nowhere more important that in the healthcare field. New research leads to new evidence, which in turn directs development of new recommendations, guidelines and treatments. In order to have a positive effect on healthcare system and accessibility, research must be translated into practice and applied in clinical settings. I strongly believe as a DNP prepared clinician, I will be a qualified professional to make such impact in the medical oncology area of practice. Furthermore, I would like to combine my passion for psychiatry and oncology, through involvement in the subspecialty of psycho-oncology.

As my capstone project I decided to dedicate my efforts to increase clinical staff's perception of safety in an adult acute care psychiatric settings. This was done by introducing portable personal alarms and measuring the safety attitudes using the Safety Attitudes

Questionnaire (SAQ), a scientifically validated screening tool developed by University of Texas. By taking a proactive approach to promptly alert others of potential or actual danger, and as a result initiate timely response, I strived to improve staff's perceived and actual safety. In order to answer the needs of our patients and staff in this ever more complex and oftentimes dangerous 
face of healthcare system in our nation, I strongly support the 2004 proposal by the American Association of Colleges of Nursing (AACN) to require the DNP degree as an entry level for all advanced practice nurses.

Apart from patient care, I would like to teach as a professor at the BSN level. My nursing career has been intertwined with the role of an educator from the very beginning, when I was nominated as the Education Officer while serving in the armed forces. It continued as I served as the Director of Staff Development (DSD) at the San Diego County Psychiatric Hospital. Teaching new nurses is a perfect opportunity to contribute to the nursing profession. By sharing own knowledge and experiences, I hope to be able to inspire others to commit to the growth and development of this most honorable and trusted profession. Serving as a mentor is a very fulfilling and rewarding role and it provides an opportunity for personal intellectual achievements being passed on to the next generation of healthcare practitioners. Furthermore, there are certain personal qualities, such as leadership skills, I feel I was able to expand by completing the DNP program at USD. My ultimate dream is to become involved in policy development in the political arena and in doing so becoming a leader in the healthcare law. I strongly believe, completion of the program will enable a dream and a vision, to become a mission, and I have committed and dedicated myself to improve today's healthcare and further promote Doctoral preparation of Nurse Practitioners. 


\begin{abstract}
The aim of this evidence-based project was to introduce portable personal alarms to all clinical staff on an acute adult psychiatric locked unit at the Mesa Vista Behavioral Health Hospital, San Diego. The purpose was to increase staff's perceived and actual safety. The project resulted in an increase of staff's perception of safety in areas such patient safety as perceived by staff, improved perception of addressing medical errors, and improved perception of learning culture at the facility. While $80 \%$ of responding staff found the concept of portable personal alarms beneficial, most agreed alternative models of alarms should be investigated, due to high sensitivity of introduced alarms. The results demonstrate significance of early detection of high risk situations in relation to safety attitudes and identified additional areas of staff's safety concerns.
\end{abstract}

\title{
Background
}

Throughout history behavioral health professionals have tried to effectively assess, accurately anticipate, successfully prevent and promptly respond to violent behavior. Violence prediction remains a complex phenomenon, especially considering its multifactorial nature (Grisso \& Applebaum, 1992). Demonstration of aggression and violence may constitute a manifestation of acute or chronic range of conditions, both psychiatric and behavioral. It is imperative to recognize crisis promptly and perceive violent behavior as an emergency.

Moreover, causes of crisis which may give rise to violence and high risk situations are frequently embedded in the structural arrangement of care, the culture of services and rather than solely dependent on patient pathology. (Fisher, 2003). 
Violence prevention is of outmost importance to healthcare providers who are required by law to protect third parties against patient violence, as evidenced by the California Supreme Court decision in Tarasoff vs Regents of the University of California in 1976. The reality of violent events in the healthcare settings, and within mental health settings in particular, requires the staff to be equipped with proper training, appropriate equipment, screening tools and knowledge about appropriate interventions necessary to safely and effectively manage crisis.

Workplace violence is associated with a negative impact on healthcare workers. A cross sectional design study by Gates, Gillespie and Succop (2011) revealed violence significantly affects work productivity and $17 \%$ of staff who were victims of workplace violence suffered symptoms consistent with Post Traumatic Stress Disorder. Moreover, the same study reported increased absenteeism and frequent turnover of staff who suffered violence at the hands of the patients.

An organization's structured proactive and reactive measures should aim to ensure safety by enhancing clinical effectiveness of staff to identify hazards and foresee risks. A linear relationship between verbal and physical aggression has been established and clinical staff need to be able to recognize, assess, then promptly and skillfully intervene during potential and actual assaults (Maier, Stava, Mowwor, Van Rybroek, \& Baumaan, 1987). Healthcare facilities often require clinical (and non-clinical) staff to enter secluded areas to provide patient care. Low traffic and visibility areas are prime locations for violence against staff since the incident is unlikely to be observed or interrupted quickly. Personal portable alarms are a well-validated simple intervention to alert other staff of actual 
and potential high risk situations and one of the best ways to protect staff from assault and violence. A wearable panic button devices or portable personal alarms enable rapid identification of location of the incident and facilitate a rapid response. The use of personal portable alarms by staff in clinical settings allows for fast onset of response system and therefore increases actual and perceived safety by clinical staff (ANA, 2012).

The Bureau of Labor Statistics estimates that 900 deaths and 1.7 million nonfatal assaults occur each year due to workplace violence across industries, which is an alarming statistic. A comparison of pre- and post-intervention survey data found an improvement in perceived violence climate factors, such as management commitment to violence prevention and employee engagement, although showed no overall change in assault rates (Lipscomb, 2006). Literature review from disciplines including criminology, occupational and public health, adult education, and mental health and psychology employees' perception of management commitment to violence prevention was associated with less workplace violence (McPhaul, 2004).

According to the ENA research, 82 percent of incidents of physical violence actually happen inside a patient's room, and most exam rooms are not outfitted with emergency alarms or panic buttons. Portable panic buttons that can be physically worn on the nurse may provide additional level of protection. In simple words of Brechner in 2011: “There's only one environmental control measure that we found that actually makes a difference in the amount of violence in a department, and that is a panic button or silent alarm." 


\section{PICO Question}

In an adult acute behavioral health inpatient locked unit do personal portable alarms increase perception of safety over a period of five weeks?

\section{Setting}

Current practice at the Sharp Mesa Vista Hospital in San Diego does not utilize personal portable alarms and relies on use of cell phones, voice/yelling and a silent alarm button located at the nursing station to alert others of crisis/emergency situation. The initial staff interviews revealed concerns with personal safety based on following factors: limited visibility/ability to monitor patients due to unit layout and in particular new location of the nursing station; difficulty of access to the alarm button located at the nursing station and lack of awareness about its functionality. In addition staff expressed concerns with ineffectiveness of phone and voice raised alarms in out of sight areas or while being attacked/choked. Furthermore, staff expressed concerns about personal safety while walking to and from car after dark.

\section{Project Plan and Implementation Process}

The Iowa Model of Research-Based Practice to Promote Quality Care was selected to guide clinical decision-making and evidence-based practice implementation from both the practitioner and organizational perspectives. The project began with conducting information interviews with key clinical and administrative staff. These interviews focused on collection of information about existing administrative structures for dealing with safety issues and general informations about existing safety procedures, policies in place. Elements addressed were presence of safety professionals, security force, committees, reporting and use of incident 
reports, workers compensation reports, patient and staff safety surveys and OSHA or Joint Commission citations. In addition structures for reporting incidents of violence were identified to see if they are standardized and well understood by clinical staff. The interviews further focused on identification of training programs for personal safety, violence prevention, seclusion and restraint reduction and existence of emergency code system such as code team for violent incidents. Interviews also focused on incident procedures for documentation, counseling, and referral to employee assistance programs (EAP) programs if in place. An environmental audit followed with focus on existing physical and architectural environment and identification of elements contributing to risks of violence. This visual inspection focused on assessment of the degree to which architectural design and facility layout, even furniture placement, may have contributed to the risk of violence. The assessment included building materials and unit décor that could contribute to harm and injury. Pre-intervention data collection using Staff Attitude Questionnaire (SAQ) was completed over one week span. These instructions included how to use, wear and where to find alarm replacements. Any staff questions were addressed in three sessions set up at different times of the day to reach out to all shifts. Post- intervention data collection with additional feedback was conducted over the next two weeks. Finally data was analyzed, interpreted and results presented in a graph format and shared with facility administration, staff and nursing students present at the facility during that time. This project was designed and evaluated by a DNP student, and introduced by the hospital's nursing leadership in collaboration with the facility leadership, under the supervision of the Medical Director and the Director of Nursing services. 


\section{Evaluation}

The project was monitored and evaluated using the SAQ Questionnaires pre and post intervention. Additional feedback form containing 5 questions was developed to provide nonscored staff input and was attached to the post-intervention SAQ.

\section{Outcomes}

The aim of the project was to increase clinical staff perception of safety by implementing portable personal alarms into clinical settings. Despite the small sample size ( $\mathrm{n}=9$ preintervention, and $n=8$ post-intervention) it may be safe to assume it was representative of the whole unit as all three shifts were represented. Although at first glance the results show decrease in three of the six main categories measured by the SAQ, it is necessary to look more closely at each specific question score and the additional feedback form. Based on the 5 question feedback form attached to the SAQ, the concept of personal alarms found acceptance in $80 \%$ of clinical staff who participated in the SAQ questionnaire. Remaining $20 \%$ of staff reported they did not chose to wear the alarms based on their pre- perceived believe in alarms not having a positive influence on safety. In the realm of Safety Climate, staff responses showed $12 \%$ increase in positive attitude when asked if they would feel safe if they were patients on the unit (marked as Safe as Patients on the graph). SAQ also revealed 12\% in staff's support of Medical Errors being addressed appropriately on the unit and 6\% increase in Learning Culture attitude. There was a considerable decrease noted in the attitudes relating to Communication channels, Receiving feedback and Reporting concerns, all relating directly to management style. This change could have been a result of recent unpopular decisions made by the leadership team, and were not 
reflective of response to the introduction of personal alarms themselves. Both Job Satisfaction and perception of Unit Management showed significant decrease in staff's support.

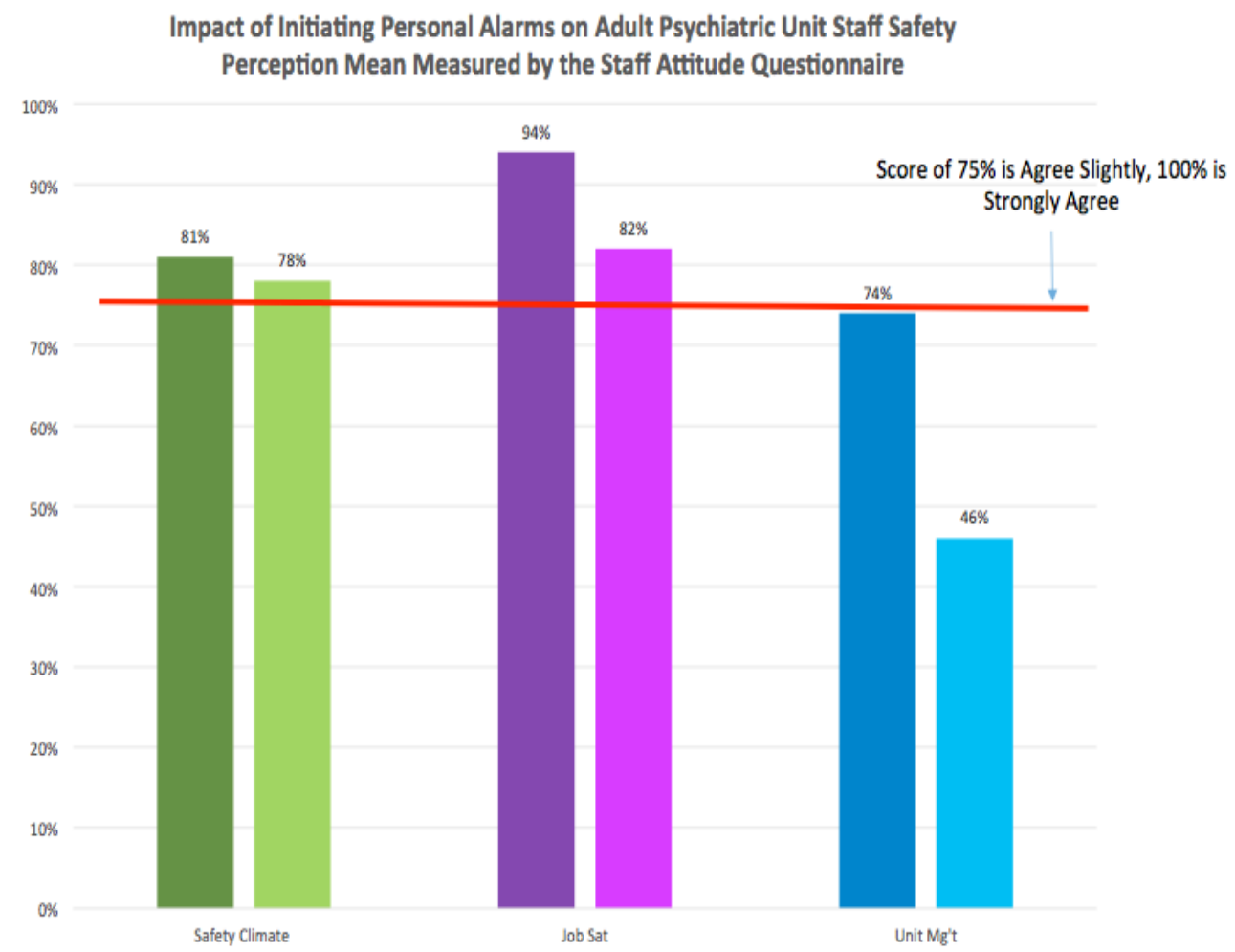

Interestingly, staff found creative alternative uses for alarms to increase personal safety outside of the unit, within the hospital environment, such as utilizing the alarms while off the unit in the parking lot after sundown. In addition, the environmental audit and staff interviews revealed additional safety hazards and concerns, which staff hopes will be taken into consideration by management while implementing future safety interventions. 


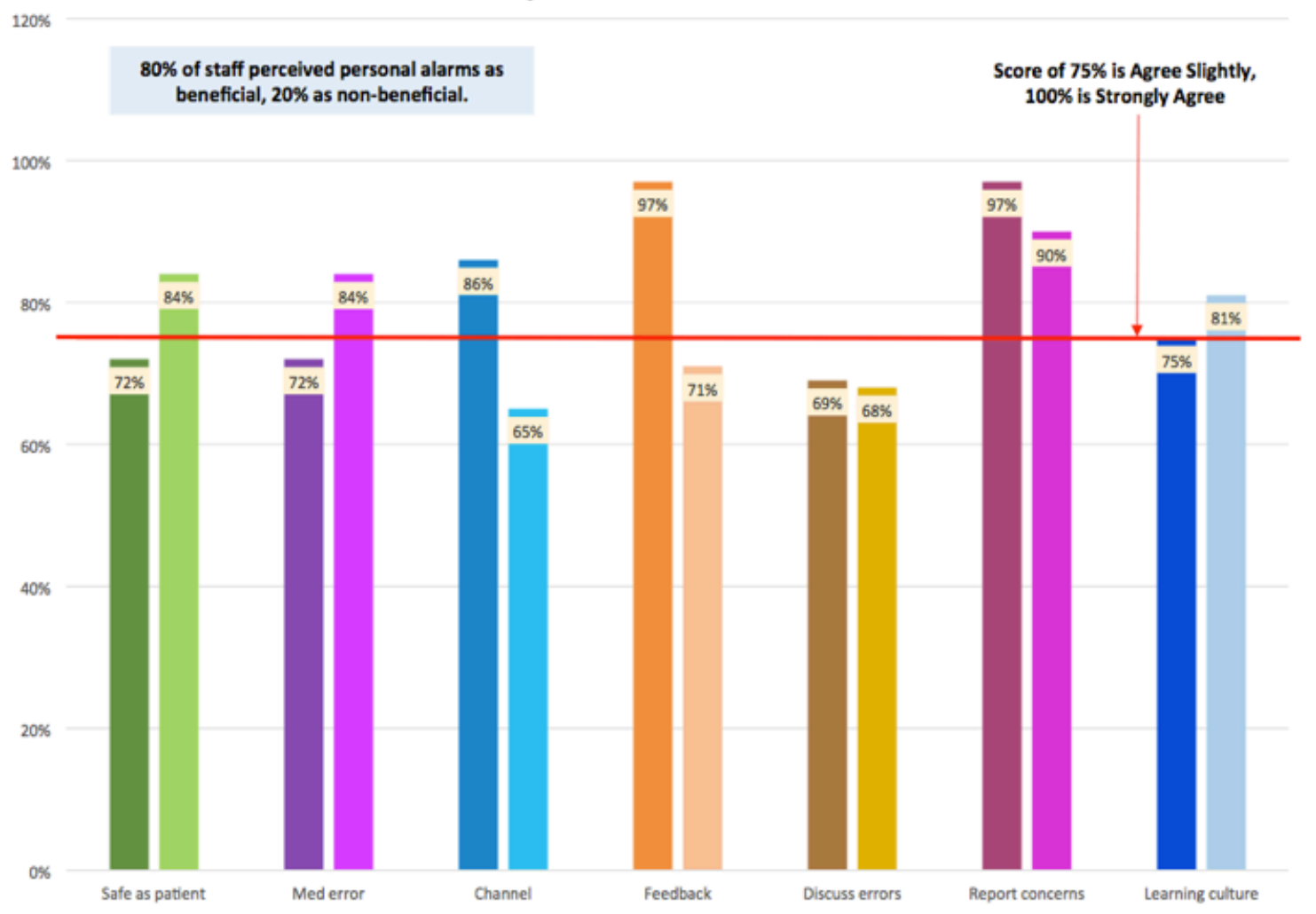

\section{Conclusions and Implications for Practice}

The importance of a violence-free workplace is important in many areas of clinical practice. Early and effective alarm system in response to actual or potential violence allows for prompt interventions. Portable personal alarms have wide application not only in behavioral health settings, but also in general healthcare sites, correctional facilities, and other public and private settings with potential for violent behaviors.

Due to short time of the project further EBP data collection should focus on additional administrative information sets to include workers compensation claims, patient incidents reports, staff and security response logs, the OSHA $300 \operatorname{logs}$, as well as other data sources to supplement limited information collected in the pilot project. 
Literature review suggests patients, their families, and/or interviews with their representatives could be potentially considered to provide insights on sources of frustration and triggers for patient violence (Allen, 2011). This in turn could help prevent high risk occurrences. Workplace violence prevention programs can also benefit from carefully constructed staff safety surveys conducted periodically (Arnetz, 2000). Such information could help to assess the level of verbal and physical violence that is not reported through the formal mechanisms (e.g. incident reports). Focus groups used as tool for assessing the perceptions of direct care staff in terms of the causes of violence, working conditions that may contribute to violence, and the understanding that staff have of safety policies could be considered and implemented. Easiest and ongoing intervention would be to invite direct care staff from all shifts to participate in the walk-around audits with open feedback format. These could ensure that staff concerns and perceptions about the environment are included in the reports and recognize staff's input and ability to have direct part in improving quality of care and increasing safety. 


\section{Closing Statement}

Through the course of my DNP study at University of San Diego, I have grown personally and professionally. I expanded my skills and knowledge base, and developed higher level or critical thinking and decision making as a health care provider. In addition the doctoral capstone project allowed me to gain understanding of healthcare change process itself, first hand. My project focused on increasing clinical staff's perception of safety in an adult acute care psychiatric settings. This was done by introducing portable personal alarms to the nursing staff and measuring safety attitudes. This was accomplished using the Safety Attitudes Questionnaire (SAQ), a scientifically validated screening tool developed by University of Texas. By taking a proactive approach to promptly alert others of potential or actual danger, and as a result initiate timely response, I strived to improve staff's perceived and actual safety. Thought the completion of the project, I was able to refine certain personal qualities, such as leadership skills and assertiveness. I believe the program has prepared me to accept leadership roles in the current healthcare arena, and play an active part in its dynamic policy and clinical practice changes. 


\section{References}

Allen, D.E., de Nesnera, A., Cummings, K., Darling, F.E. (2011). Transforming the culture of caring. Journal of Psychosocial Nursing and Mental Health Service, 49(1), 45-49.

American Nurses Association. (2012). Workplace violence. Retrieved from: nursingworld.org/ MainMenuCategories/Policy-Advocacy/State/Legislative-Agenda-Reports/StateWorkplaceViolence

Arnetz, J. E. \& Arnetz, B. B. (2000) Implementation and evaluation of a practical intervention programme for dealing with violence towards health care workers. Journal of Advanced Nursing 31, 668-680.

Bureau of Labor Statistics. (2006). Survey of workplace violence prevention, 2005.

Washington, DC: United States Department of Labor, Retrieved from: www.bls.gov/iif/ oshwc/osnr0026.pdf

California Hospital Safety and Security Act. CAAB 508. §1257.7 and 12.57.8. (1993)

Retrieved from: www.leginfo.ca.gov/pub/93-94/bill/asm/ab_0501-0550/ ab_508_bill 931008_chaptered

Casteel, C., Peek-Asa, C., \& Nocera, M., (2009). Hospital employee assault rates before and after enactment of the California Hospital Safety and Security Act. Annals of Epidemiology, 19, 125-133.

Centers for Disease Control and Prevention, \& National Institute for Occupational Safety and Health. (2002). Violence: Occupational hazards in hospitals. Retrieved from www.cdc.gov/niosh/docs/2002-101/ 
Centers for Disease Control and Prevention, \& National Institute for Occupational Safety and Health. (2006). Workplace violence prevention strategies and research needs. Retrieved from: www.cdc.gov/niosh/docs/2006-144/pdfs/2006-144.pdf

Crisis Prevention Institute. (2009). Section PC.03.05.17. In Joint commission standards on restraint and seclusion/Nonviolent Crises Intervention ${ }^{\circledR}$ training program (p 7). Retrieved from www.crisisprevention.com/CPI/media/Media/Resources/alignments/JointCommission-Restraint-Seclusion-Alignment-2011.pdf

Emergency Nurses Assocation. (2010). ENA toolkit. Workplace violence. Retrieved from www.ena.org/IENR/ViolenceToolkit/Documents/toolkitpg1.htm

Emergency Nurses Assocation. (2009). 50 state survey workplace violence laws protecting health care professionals. Retrieved from: www.ena.org/IENR/Documents/State \%20Survey\%20-\%20Laws\%20Protecting\%20Health\%20Care\%20Professionals.pdf

Gates, D., Gillespie, G., Smith, C., Rhode, J., Kowalenko, T., \& Smith, B. (2011). Using action research to plan a violence prevention program for emergency departments. Journal of Emergency Nursing, 37(1), 32-39.

Grisso, T., \& Appelbaum, P. (1992). Manual: Understanding treatment disclosures. Worcester MA: University of Massachusetts Medical Center.

Hodgson, M.J., Reed, R., Craig, T., Murphy, F., Lehmann, L., Belton, L., \& Warren, N. (2004). Violence in healthcare facilities: Lessons from the Veterans Health Administration. Journal of Occupational and Environmental Medicine, 11(46), 1158-1169. 
Hodgson, M.J., Warren, N., Mohr, D., Meterko, M., Charns, M., Osatuke, K., Dyrenforth, S.,...

Wilson, R. (2008, October). Violence assessment and intervention in the Veterans Health Administration. Paper presented at the international conference Violence Prevention in Healthcare, Amserdam.

Laws of New York. (2007) Workplace violence prevention law: Section 27-b of State Labor Law. Retrieved from: www.labor.state.ny.us/workerprotection/safetyhealth/ $\underline{\text { workplaceviolence.shtm }}$

Lipscomb, J., McPhaul, K., Rosen, J., Geiger Brown, J., Choi, M., Soeken, K... Porter, P. (2006). Violence prevention in the mental health setting: The New York state experience. Canadian Journal of Nursing Research, 38(4), 96-117.

Lipscomb, J., London, M., \& McPhaul, K. (2007). Responding to the epidemic of workplace violence in public sector health care and social service workplaces. In M. Lies (Ed.), Preventing and managing workplace violence - legal and strategic guidelines. Chicago, IL: ABA Book Publishing.

Lipscomb, J., Chen, Y., Geiger Brown, J., Flannery, K., London, M., McPhaul, K., (2012). Workplace violence prevention in state-run residential addiction treatment centers. Work: A Journal of Prevention, Assessment \& Rehabilitation, 42(1), 47-56. doi: 10.3233/ WOR-2012-1330.

Maier GJ, Stava LJ, Morrow BR, Van Rybroek GJ, Bauman KG. (1987). Hospital Community Psychiatry, 38(5):520-4. 
McPhaul, K. M. (2008). Environmental evaluation for workplace violence in healthcare and social services. Journal of Safety Research 39(2), 237-250. McPhaul, K. M. (2008). Environmental evaluation for workplace violence in healthcare and social services. Journal of Safety Research 39(2), 237-250.

Spector, P, Coulter, M., Stockwell, H.G., \& Matz, M. (2007). Perceived violence climate: A new construct and its relationship to workplace physical violence and verbal aggression, and their potential consequences. Work \& Stress: An International Journal of Work, Health \& Organizations. 21 (2), 117-130.

Wassell, J.T. (2009).Workplace violence intervention effectiveness: A systematic literature review. Safety Science, 47(8), 1049-1055. 


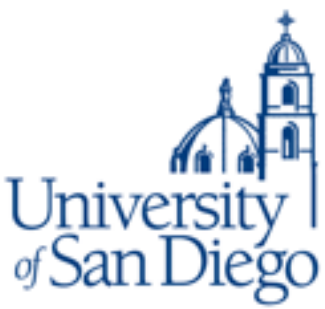

\section{Institutional Review Board \\ Project Action Summary}

Action Date: March 9, 2016

Note: Approval expires one year after this date.

Type: __New Full Review

New Expedited Review

Continuation Review X Exempt Review Modification

Action:

X_Approved

Approved Pending Modification

Not Approved

Project Number:

Researcher(s):

2016-03-136

Komelia A Kopec DNP student SON

Dr. Michael Terry Fac SON

Project Title: Improvement of Staff Safety Utilizing a Staff Safety Attitude Questionnaire

Nate: We send IRB correspondence regarding student research to the faculty advisor, who bears the ultimate responsibiilty for the conduct of the research. We request that the facuity advisor share this correspondence with the student researcher.

Modifications Required or Reasons for Non-Approval

None

The next deadline for submitting project proposals to the Provost's Office for full review is N/A. You may submit a project proposal for exped ited review at any time.

\section{Dr. Thomas R. Herrinton}

Administrator, Institutional Review Board

University of San Diego

herrinton@sandiego.edu

5998 Alcalá Park

San Diego, Califomia 92110-2492

Office of the Executive Vice President and Provost

Hughes Administration Center, Room 214

5998 Alcalá Park, San Diego, CA 92110-2492

Phone (619) 260-4553 • Fax (619) 260-2210 • www.sandiego.edu 


\section{$\overline{\text { SHARP. Mesa Vista }}$}

To: $\quad$ Institutional Review Board, University of San Diego

From: Loralie Woods, MSN, RN-BC

Re: $\quad$ Use of Clinical Data

KORNELIA KOPEC has our support to begin their scholarly practice project at the Sharp Mesa Vista Hospital as part of his/her coursework for the DNP Program at the University of San Diego. Mrs. Kopec has agreed to cleanse all data of any patient or institutional identifiers, and we understand that she will request to use data from this experience for publications and professional presentations.

If you have any questions, please do not hesitate to contact me at $\underline{858-836-8736}$ or email at loralie.woods@sharp.com

Sincgrely, 4 alie whols

Manager of Nursing Education

Sharp Mesa Vista Hospital 


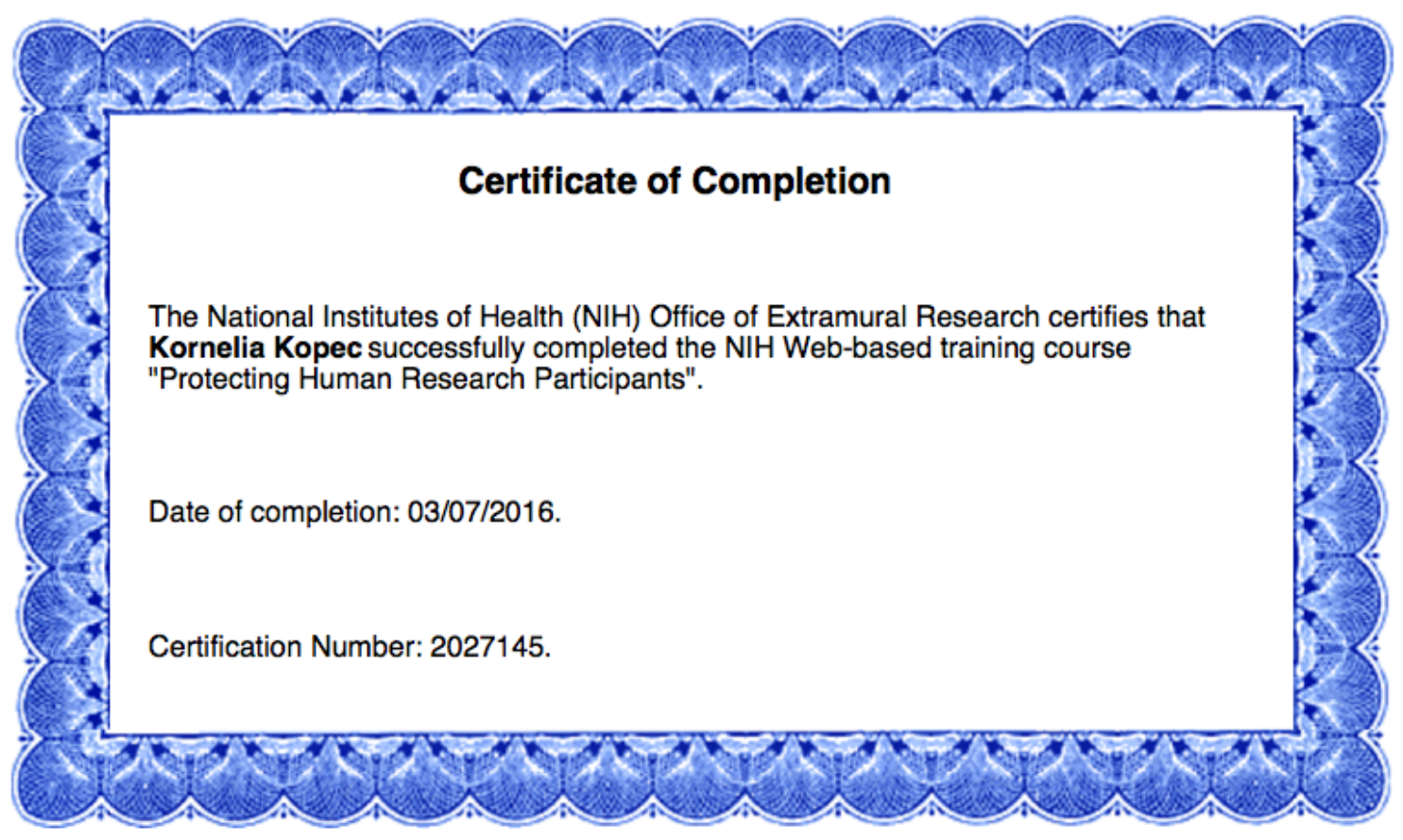


UTHealth

The University of Texas

Health Science Center at Houston
Medical School

University of Texas at Housten-Memorial Hermann Center for Hesitheare Quality and Safety

November 5, 2015

Dear Kornelia Kopec,

You have our permission to use any of the following Safety Attitudes Questionnaires and the corresponding scoring keys:

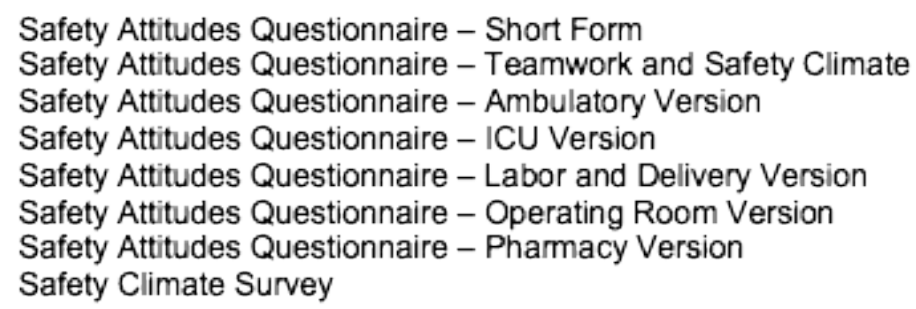

Please note, we do not have editable versions for any of the SAQ surveys but feel free to modify the surveys to meet your research endeavors.

Respectfully,

University of Texas at Houston-Memorial Hermann

Center for Healthcare Quality and Safety Team

\footnotetext{
Q410 Fanain Screer

LTPS Suite 1100

Houston, TX 77030

bttps: $/ /$ mod.uthedu/chcs $/$
} 


\section{Safety Attitudes: Frontline Perspectives from this Patient Care Area}

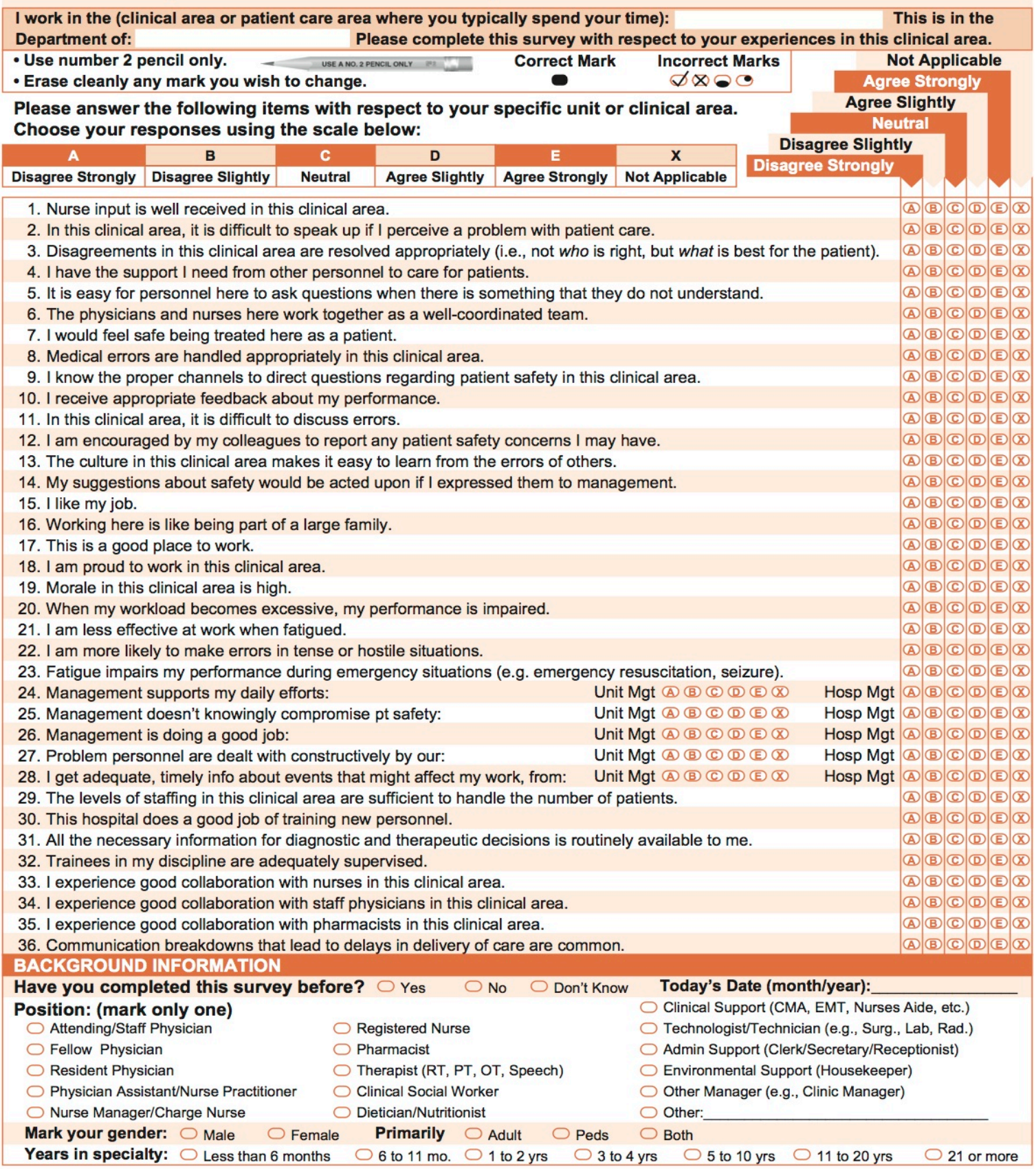

Thank you for completing the survey - your time and participation are greatly appreciated. 
Dear Kornelia Anna Kopec, RN, BSN,

This message serves as confirmation that you have agreed to present the following Presentation at 49 th Annual Communicating Nursing Research Conference:

Presentation ID: $\quad 10832$

Title: Prediction and Prevention of Violent Patient Behavior

Session Day/Time: Saturday, April 9, 2016: 08:00 AM - 12:00 PM

Posters will be on display for an entire morning or an entire afternoon. Presenters are asked to be available for the hour designated in the conference schedule for Poster Viewing.

Thank you. 


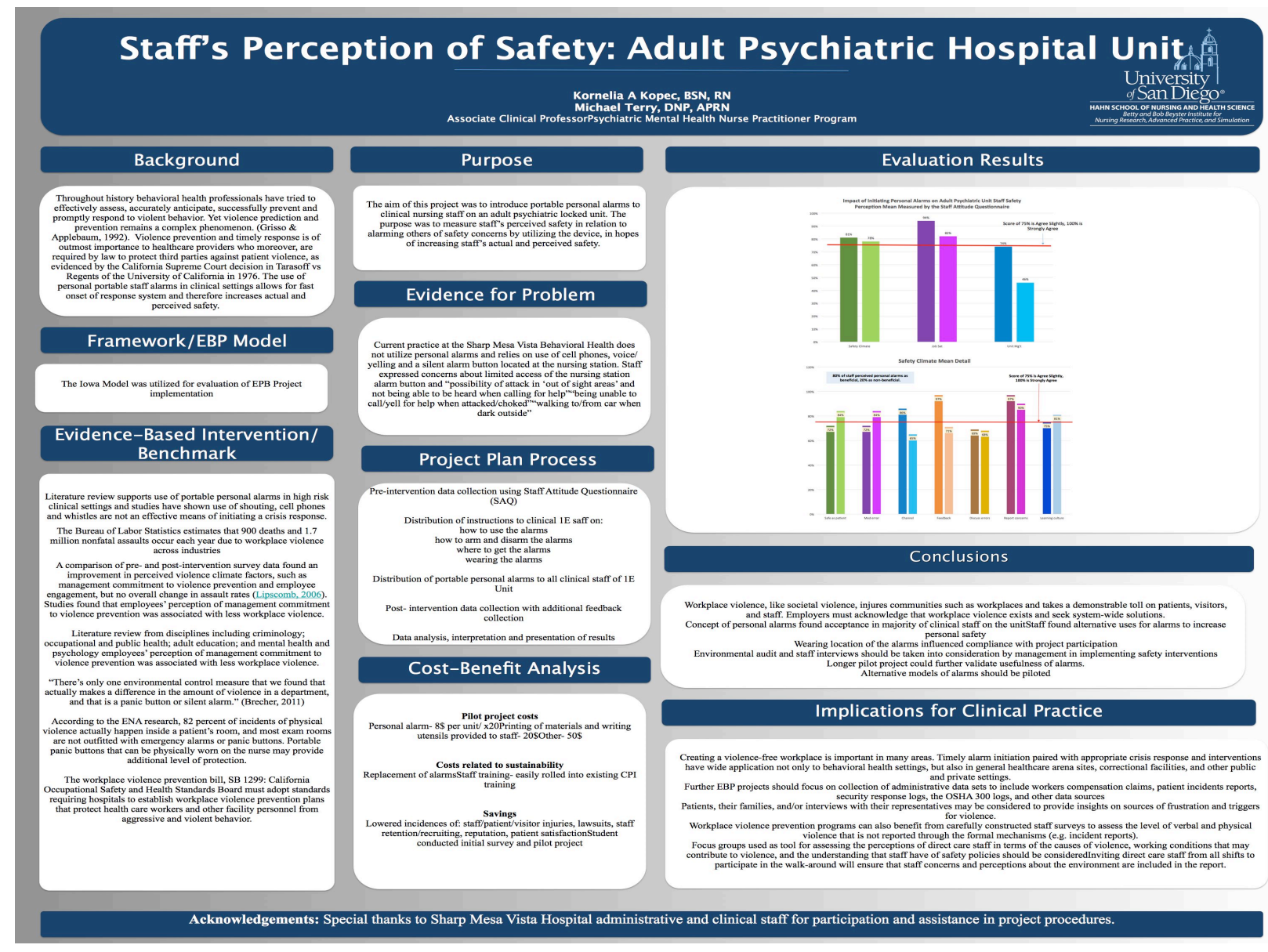

